\section{Antegrade vs retrograde insertion introducer for guided intubation in needle laryngos- tomized patient}

To the Editor:

We read with interest the prophylactic use of percutaneous high frequence jet (HFJ) ventilation for difficult intubation in a patient who underwent coronary artery bypass grafting. ' Because the vocal cords were not visualized by laryngoscopy and fiberoptic intubation apparatus was not available, tracheal intubation was achieved with an introducer passed behind the epiglottis.

Our experience corroborates others ${ }^{2-10}$ that guided tracheal intubation is a useful technique in difficult intubations, sometimes even more helpful than fiberoptic intubation. ${ }^{6-7}$ Dr. McLellan and his colleagues did not elaborate the duration of their procedure nor did they describe the difficulty encountered. We believe it would be easier and faster if a soft introducer were inserted retrogradely via the already existing HFJ cannula and a firm introducer were slid over the soft introducer to serve as a stylet. This technique has been described in detail by us. ${ }^{9}$ If this were done, it would not be necessary to paralyze the patient before securing the airway nor would one need a fiberoptic bronchoscope or a jet ventilator.

In reported cases ${ }^{3}$ using translaryngeal guided intubation (TLI), the cardiovascular variables were stable throughout the cricothyroid puncture and guided intubation.

Prolonged laryngoscopy is very stressful and therefore is of more concern in patients with ischaemic cardiac diseases. Additionally, the needle catheter used for TLI is much smaller and hence much less traumatic than HFJ.

\author{
Kwa-Kou King MD \\ Long-Fong Wang MD \\ Absanul K. Khan MD \\ Daniel J. Wooten MD \\ Charles R. Drew University of Medicine and Science \\ Department of Anesthesiology \\ 12021 South Wilmington Avenue \\ Los Angeles, CA 90059

\section{REEERENCES} \\ 1 McLellan I, Gardon P, Khawaja S, Thomas A. Percu- \\ taneous transtracheal high frequency jet ventitation as an \\ aid to difficult intubation. Can J Anesth 1988; 35 : \\ 404-5.
}

2 King $H K$. Translaryngeal guided intubation - a lifesaving technique. A review and case report. Anesth Sinica 1984; 22: 279-87.

3 Casthely $P A$, Fyman $P N$, Ergin $M A$, Griepp $R$, Wold $G L$. Retrograde intubation in patients undergoing open heart surgery. Can Anesth Soc J 1985; 32: 661-4.

4 Freund PR, Rooke A, Schmid H. Retrograde intubation with a modified Eschmann stylet. Anesth Analg 1988; 67: 605-6.

5 Barriot $P$, Riou B. Retrograde technique for tracheal intubation in trauma patients. Crit Care Med 1988; 16: 712-3.

6 Carlsan CA, Perkins HM, Veltkan PS. Solving a difficult intubation. Anesthesiology 1986; 64: 537-8.

7 Lechman MJ, Donahoo JS, MacVauch H. Endotracheal intubation using percutaneous retrograde guidewire inscrtion followed by antegrade fiberoptic bronchoscopy Crit Care Med 1986: 14: 589

8 King HK, Chen FM, Khan AK, Wooten DJ. Translaryngeal guided intubation solved a critical airway problem. J Clin Anesth; 1989 (in press).

9 King $H K$, Wang LF, Khan AK, Woolen DJ. Translaryngcal guided intubation for difficult intubation. Crit Care Med 1987; 15: 869-71.

10 Harmer $M$, Vaughan $R S$. Guided blind oral intubation. Anaesthesia 1980; 35: 921

\section{An alternative use for a nasotracheal tube}

The opinions and assertions contained herein are the private views of the authors and are not to be construed as reflecting the views of the Department of the Army ar the Department of Defense.

To the Editor:

A general anaesthetic conducted in the prone position is fraught with many hazards, not the least of which is the positioning and management of the endotracheal tube.

We have made extensive use of an orally inserted nasal RAE tube for patients in the prone position and find this a preferable alternative to a straight tracheal tube. The preformed curvature of the nasal RAE tube gives greater resistance to kinking and allows the circuit to extend easily off the head of the operating table. The anaesthetist has ready access to the tracheal tube for suctioning and detection of a disconnect (Figure). 